\title{
GEOPOLITICAL TENSIONS, OPEC NEWS, AND THE OIL PRICE: A GRANGER CAUSALITY ANALYSIS*
}

\author{
TENSIONES GEOPOLITICAS, NOTICIAS OPEP, Y EL PRECIO DEL \\ PETROLEO: UN ANALISIS DE CAUSALIDAD GRANGER
}

\section{ANTONIO FERNANDOIS**}

Central Bank of Chile

\section{CARLOS A. MEDEL ${ }^{* * *}$}

Central Bank of Chile

\begin{abstract}
To what extent do geopolitical tensions, supply disturbances, and unexpected news in the Organisation of the Petroleum Exporting Countries (OPEC) and major oil-producer countries affect the oil price? Are oil price forecasters aware of these tensions? Do these tensions affect forecasters' consensus when making their predictions? Is there a difference between news coming from OPEC countries versus other major oil exporters? In this article, we analyse the influence of geopolitical tensions, news, and events in major oil producers on the Brent oil price, its forecasts, and the dispersion of those forecasts. We empirically test these hypotheses by introducing and making use of a unique media-based measure of geopolitical tensions accounting for supply crunches and expansions for the 2001-12 period, by means of Granger causality. We found evidence suggesting that overall geopolitical
\end{abstract}

* We thank Ercio Muñoz for his kind provision of the dataset used in López and Muñoz (2012). We also thank comments and suggestions to Rolando Campusano, Gabriela Contreras, Ashita Gaglani, Pablo Medel, Ercio Muñoz, Damián Romero, an anonymous referee of the Working Paper series of the Central Bank of Chile, and an anonymous referee of the Economic Analysis Review. We also thank Consuelo Edwards for editing services. Nevertheless, we exclude them for any error or omission that remains at our own responsibility. This article is an extensive revision of the Working Paper 805 , Central Bank of Chile. The views and ideas expressed in this paper do not necessarily represent those of the Central Bank of Chile or its authorities. Any errors or omissions are the responsibility of the authors.

** E-mail: afernandois@bcentral.cl.

*** Corresponding author. E-mail: cmedel@bcentral.cl. 
tensions affect the current level of oil price, its forecasts, and the dispersion of those forecasts. More remarkably, when separating between OPEC and non-OPEC news, we found that the former affect oil price forecasts and its consensus, and at the same time, the current oil price determine oil-based news on OPEC countries. Moreover, non-OPEC news affect the current and future oil price level and neither the forecast nor the dispersion of those forecasts its affected by the level. All these results imply that geopolitical tensions in a broader sense affect oil prices, and OPEC news should be read jointly with other geopolitical tensions as oil price drivers-and not as an isolated news generator affecting oil prices. This weakens the hypothesis of OPEC as a price setter in the global oil market whose behaviour, in turn, seems a matter for forecasters. These results are important suggesting that, in order to keep track of oil price dynamics, one needs to account for a more general context of geopolitical tensions beyond OPEC countries, relying on signals and externalities that are not necessarily based on economic rationale.

JEL-Codes: C12, C22, E66, Q41.

Keywords: Oil-producer countries, OPEC, oil price, Granger causality.

\section{Resumen}

¿En qué medida las tensiones geopolíticas, disrupciones de oferta, y noticias inesperadas de la Organización de Países Exportadores de Petróleo (OPEP) y principales países productores de petróleo afectan el precio del petróleo? ¿Están conscientes los pronosticadores del precio del petróleo de estas tensiones? ¿Afectan estas tensiones el consenso de los pronosticadores al hacer sus proyecciones? ¿Existe alguna diferencia entre las noticias provenientes de los países de la OPEP y otros grandes exportadores de petróleo? En este artículo, analizamos la influencia de las tensiones geopolíticas, noticias, y eventos en los principales productores de petróleo sobre el precio del petróleo Brent, sus proyecciones, y la dispersión en torno a esas proyecciones. Empíricamente probamos estas hipótesis mediante la introducción y el uso de una medida única basada en los medios de prensa de las tensiones geopolíticas que contabiliza por reducciones y expansiones de oferta para el período 2001-12, mediante causalidad de Granger. Encontramos evidencia sugiriendo que las tensiones geopolíticas, en general, afectan el nivel actual del precio del petróleo, sus proyecciones, y la dispersión en torno a esas proyecciones. Notablemente, al separar entre las noticias de la OPEP y las no OPEP, encontramos que las primeras afectan las proyecciones del precio del petróleo y su consenso 
y que, al mismo tiempo, el precio actual del petróleo afecta las noticias en los países de la OPEP. Además, las noticias no OPEP afectan el nivel actual y futuro del precio del petróleo, y ni el pronóstico ni la dispersión de esos pronósticos se ven afectados por el nivel actual. Todos estos resultados implican que las tensiones geopolíticas en un sentido más amplio afectan el precio del petróleo, y que las noticias OPEP deben leerse conjuntamente con otras tensiones geopolíticas como determinantes del precio del petróleo, y no como un generador de noticias aislado que afecta el precio del petróleo. Esto debilita la hipótesis de la OPEP como un fijador de precios en el mercado mundial del petróleo cuyo comportamiento, a su vez, parece ser relevante para los pronosticadores. Estos resultados son importantes, y sugieren que, para realizar un seguimiento de la dinámica de los precios del petróleo, se debe tener en cuenta un contexto más general de tensiones geopolíticas más allá de los países de la OPEP, apoyándose en señales y externalidades que no se basan necesariamente en la lógica económica.

Códigos JEL: C12, C22, E66, Q41.

Palabras clave: Países productores de petróleo, OPEP, precio del petróleo, causalidad de Granger.

\section{INTRODUCTION}

Crude oil and its processed liquids have been the most essential commodities traded worldwide during the last half-century. Its undoubted importance is owed to, among other reasons, early massive specific investments and the development of technologies using it as a primary fuel, particularly in the automobile and transport sectors in general. The long-lasting oil dependence of the largest economies of the world, added to a certain degree of geographic concentration and cultural cohesion of some of the biggest oil-producing countries which, at the same time, suffer high political instability threats and uprisings, carry particular and specific features associated to this massive, global market.

To these geopolitically-based externalities, there is the existence of the Organisation of the Petroleum Exporting Countries (OPEC) compounded by 14 states primarily located in the Middle East and Africa. ${ }^{1}$ Its main aim is "to coordinate and unify policies of its member countries", ensuring "a fair return on capital for those investing in the

1 Algeria, Angola, Congo, Ecuador, Equatorial Guinea, Gabon, Iran, Iraq, Kuwait, Libya, Nigeria, Saudi Arabia, United Arab Emirates, and Venezuela. 
petroleum industry" (OPEC, 2012). This leads to think of OPEC as convenor into setting quotas and carrying the unpleasant label of a worldwide recognised cartel (see Gülen, 1996; Griffin and Xiong, 1997; Jones, 1990; Kaufmann et al., 2004, and Brémond et al., 2012, for details). Some other big market players such as Brazil, Canada, China, Mexico, Russia, and the United States are not OPEC members and coincide with a record of, on average, less political tensions, threats, and realisations in the last decades. Thus, it is relevant to delve into the particular effect of unexpected geopolitical tensions and news related to major oil producers and disentangling the news related to OPEC on oil prices within a wider environment of threats, tensions, political instability, and oil supply news.

To that end, this article questions to what extent do geopolitical tensions, supply disturbances, and unexpected news in the OPEC and other major oil-producer countries affect oil price? Are oil price forecasters aware of these tensions? Do these tensions affect forecasters' consensus when making their predictions? Is there a difference between news coming from OPEC countries versus other oil exporters?

We empirically test these hypotheses making use of a unique, purposely built mediabased measure of geopolitical tensions accounting not only for supply crunches but also for expansions in the 2001-12 period, by means of Granger causality. Geopolitical tensions are defined as the risks posed by tensions between states that affect a peaceful course of relations, which can be composed of threats plus realisations such as riots, wars, or terrorist acts. However, our unique measure of tensions includes also news related to oil supply expansions -entering with the corresponding opposite sign of geopolitical risks. This is the case of new announcements on discoveries and site exploration as well as public, explicit efforts to improve diplomatic relations between highly tensioned countries.

Our measure is the result of adding (or subtracting when needed) 10 dummy variables associated with news relevant to the oil market as suggested by its sources (Bloomberg, The Wall Street Journal, Financial Times, and the United States Energy Information Administration). One of these dummy variables is exclusively referred to OPEC news - which is composed by positive and negative integers. To stress out the informational content of the newly proposed geopolitical tensions and OPEC's news measure, we analyse its effect not only on the current Brent oil price but also on its forecast and dispersion, as included in the Consensus Forecast survey.

Three base hypotheses are examined and supported by testing the Granger causality the other way around to determine full independence or a feedback relationship between variables. The first hypothesis is if the overall (OPEC plus non-OPEC) geopolitical tensions and news Granger cause ${ }^{2}$ current oil prices. The second hypothesis is if the same measure causes oil price forecasts, and a third one if the same occurs for forecast

2 Although the meaning of "Granger causality" is different to ordinary "causality", we henceforth use the latter interchangeably with the former term. 
dispersion (consensus). If the geopolitical tensions and news measure is capturing well the timing and intensity of tensions, it is expected that this variable will cause all oil-related series. As a measure of unexpected events, and given the relevance of oil for mentioned exporting economies, it is allowed, however, that both forecasts and its dispersion could actually cause geopolitical tensions in a feedback sequence of processes. If this is not the case, the measure is completely exogenous and formed independent of the oil market, capturing well geopolitical tensions and unexpected news.

We found evidence suggesting that overall geopolitical tensions and news affect the current level of oil price, its forecasts, and the dispersion (consensus) of those forecasts. More remarkably, when distinguishing between OPEC versus non-OPEC news, we found that the former affect oil price forecasts and their consensus, and at the same time, the current oil price determines oil-based news in OPEC countries. Moreover, non-OPEC news affect the current and future oil price level and neither the forecast nor the dispersion of those forecasts its affected by the level. All these results imply that geopolitical tensions and news in a broader sense affect oil prices, and OPEC news should be read jointly with other geopolitical tensions as oil price drivers - and not as an isolated news generator. This weakens the hypothesis of OPEC as a price setter in the global oil market whose behaviour, in turn, seems a matter for forecasters. Moreover, it is the current oil price which affects the OPEC-based news. Some similar qualitative results are found in Alhajji and Huettner (2000), Smith (2005), and Almoguera et al. (2011) when analysing OPEC behaviour.

These results are important suggesting that, in order to keep track of oil price dynamics, it is necessary to account for a more general context of news and geopolitical tensions beyond OPEC countries, relying on signals and externalities that are not always based on economic rationale.

The remaining of the article proceeds as follows. In Section 2 we review the related literature in various dimensions: different measures of geopolitical tensions and news, and broad analyses of oil market in general and OPEC in particular. In Section 3, we describe the dataset as well as the econometric challenges of dealing with short sample and persistent time series. In Section 4 we present all the econometric results. Finally, Section 5 concludes.

\section{LITERATURE REVIEW}

There is a wide branch of research analysing the oil market beyond the boundaries of Economics. However, despite all types of methodologies and model sophistication used to understand the dynamics of oil market, we proceed considering one of the most striking time-series econometrics tools: Granger causality (Granger, 1969, 1980, 2004). As emphasised by Barrett and Barnett (2013), Granger causality is a tool designed to measure whether a variable affects another anticipatedly, but not for testing a specific mechanism. This distinction is important because a huge related 
literature focus on the behaviour of big oil-market players, specially OPEC, under several assumptions setting and ultimately testing a specific mechanism in that finds that OPEC countries act as a cartel. Granger causality has the advantage to test the relationship between variables in a naïve, agnostic, model-free way -still being empirically relevant for analysing the oil market. This approach has also been used for similar purposes in, for example, Gülen (1996) and Kaufmann et al. (2004). Gülen (1996) finds evidence supporting output coordination among OPEC members especially in the output rationing era from 1982 to 1993, thus suggesting that OPEC did act as a cartel. Kaufmann et al. (2004) find that OPEC capacity utilisation, quotas, and the degree in which quotas are exceeded, Granger cause real oil prices, but real oil prices do not cause these variables for the 1986-2000 period.

Another approach used to analyse the anticipated effect of one variable on another is the events study. This methodology has been used in, for example, Demirer and Kutan (2010) and Lin and Tamvakis (2010). ${ }^{3}$ However, in order to isolate the impact of one variable on another, all other possible effects must be controlled for. An alternative to numerous and virtually unknown controls is the use of high frequency data. Given our availability of daily news related to geopolitical tensions but with an uncertain realisation -this is, availability of news published on a specific day commenting on a supply crunch during the week, month, or an unspecified "short-term" horizon-, our analysis is based on monthly-frequency data and controlling for up to six months of possible impact. Consequently, given our econometric setup, event study does not appear appropriate for our purposes.

The challenge when analysing geopolitical tension and its realisations such as military and diplomatic conflicts, riots, and wars, plus other manifestations in the form of threats, start with its measurement. Nowadays, the literature relies on counting news of reputed media containing certain keywords or sentences meeting a set of preconceived conditions. This is the approach taken by the well-known (global) Economic Policy Uncertainty (EPU) index developed in Baker et al. (2016). Previously, Saiz and Simonsohn (2013) proposed the econometric conditions which Internet-based text data must fulfil in order to create reliable indicators, comparable to existing numerical ones. Caldara and Iacoviello (2018) also take the approach of counting key words and sentences to derive an indicator of global geopolitical risk considering a wider definition of geopolitical risk than EPU from newspapers. The indicator is built in a three-step process of definition, measurement, and audit. This latter process is important because it involves a human-based revision process -a key step to build our ad-hoc measure, which is fully human-based. Notice that this kind of indicators could be much improved with machine learning methods and software capable of performing word counting or text mining analysis when information is

3 Both articles, using a very similar time span (1982-3 to 2008) analyse the effect of OPEC's influence on prices, finding an influence on abnormal returns in crude oil spot and futures markets. 
more blurred (see Bholat et al., 2015, for a reference). Also available is a new kind of data, such as Twitter messages and other Internet-based data. ${ }^{4}$

There are already available some proxies built to measure the unobservable geopolitical risks. Bloom (2009) makes use of the stock market's realised and implied volatility (VIX) to analyse the impact of an uncertainty shock to the real economy. In turn, Bachmann et al. (2013) use survey-based forecasts to better capture the crosssectional differences at a business-level uncertainty. Jurado et al. (2015) exploit the information contained in the purely unforecastable component of the forecast value of a big number of variables, whereas Scotti (2016) exploits the dispersion around the state of the economy to differentiate between news and uncertainty. Nevertheless, neither of these indicators measures geopolitical tensions and associated risks specifically posing a threat to the oil supply and, instead, they are measuring a wider set of events.

Our measure, in turn, is specially designed to measure the same kind of risks but circumscribed to the oil market. This makes that, at least, three out of ten dummy variables considered enter our measure and are not included in mentioned indicators, namely, the United Nations Oil for Food Program announcements, the use of the United States Strategic Petroleum Reserve, and new announcements on discoveries and site exploration. In this sense, the analysis contained in this article is unique and so, we extend the econometric analysis to oil price forecasts and their dispersion to stress out the informational content of our proposed measure.

\subsection{The effect of geopolitical tensions on the oil market}

The analysis of geopolitical risks on the oil market, however, is not new in the literature. Recently, Antonanakis et al. (2017) analysed the impact of uncertainty shock (as measured with the Caldara and Iacoviello (2018)'s, geopolitical risk index) on the stock-oil returns covariance. The results reveal that geopolitical risks-broadly defined, and not specifically referred to the oil market-triggers a negative effect on oil returns and volatility, and to a lesser extent to the stock (S\&P500)-oil returns covariance. It is commonplace in the literature to proxy geopolitical tensions with a wide range of uncertainty indexes and, more scarcely, with oil-specific uncertainty measures. One exception of the latter kind of research is Joo and Park (2017). By making use of GARCH-in-mean specification, the authors find that the uncertainty of stocks (in the United States, Japan, South Korea, and Hong Kong) and oil returns carry significant negative time-varying effects of uncertainty over returns in sub-periods comprehended between 1995 and 2015.

4 Recently, Burggraf et al. (2019) analysed the effect of Twitter messages of the President of the United States on stock prices and VIX for the sample covering September 2018 to May 2019 -a total of 224 tweets. By means of Granger causality, the authors provide evidence of the one-way causality of the President's tweets affecting negatively stock returns and positively the VIX indicator. 
Kang and Ratti (2013a) claim that oil price shocks and EPU are interrelated and influence stock market returns in the United States. The authors argue that a positive oil-market-specific demand shock significantly raises EPU and reduces real stock returns. Also, Bekiros et al. (2015) find that EPU information does matter in predicting changes in oil prices. Moreover, Kang and Ratti (2013b) find that oil-specific demand shocks account for $31 \%$ of conditional variation in the EPU. Similarly, Maghyereh et al. (2016) make use of a series of implied volatility indexes in 11 major stock exchanges to investigate the directional connectedness between oil and equities between 2008 and 2015. The results support episodic bi-directional information spillovers largely dominated by the transmission from the oil to equity markets, and not the other way around. Antonanakis et al. (2014) also examine the dynamic relationship between changes in oil prices and the EPU over 1997 to 2013, finding a negative feedback relationship between oil price shocks and EPU shocks.

More related to geopolitical tensions and violent conflict, particularly terrorism and wars, Kollias et al. (2013) finds that wars have a significant negative effect on the covariance between oil price and returns of four big stock markets (S\&P500, the European DAX, CAC40, and FTSE100). Interestingly, terrorist incidents have an impact in just two indexes; CAC40 and DAX. Guidolin and La Ferrara (2010) find that, especially in the Middle East, oil futures systematically exhibit a downturn in response to conflicts in this region, analysing 101 events with the case study methodology. Some other articles highlight how terrorism deteriorates economic sentiment (Drakos and Kallandranis, 2015) and lower income per capita growth (Gaibulloev and Sandler, 2009).

Thus, the literature associates oil price shocks as a trigger to general uncertainty, but this relationship is evolving across time and is dependent on one-off events such as terrorist attacks and violent conflicts. In this article we partially support this view by finding that oil prices cause tensions and news in OPEC-countries only. Moreover, it is a wider spectrum of geopolitical tensions and news that cause oil prices, it forecasts and the dispersion around those forecasts. So, it is likely that non-OPEC tensions and news increase global uncertainty (as well as stocks, economic sentiment, and income, among others) through oil prices rather than tensions and news coming from OPEC countries. This important distinction is possible to make thanks to the construction of our newly proposed, oil-specific measure of geopolitical tensions and news.

\subsection{The economics of OPEC countries}

The OPEC was established in Baghdad, Iraq, and effective as from January 1961. Since then, a lot of attention has been attracted to a particular OPEC conference scheduled twice a year whose outcome consists of a market quota setting for participant countries. There is much speculation in the days surrounding these conferences as it supposedly is the price setting mechanism managed by OPEC. A long-standing research in this matter possibly begins with Griffin and Teece (1982), MacAvoy (1982), and 
Draper (1984), when analysing the effect of this meeting outcome-decoded as an increase, no change, or decrease in quota-on oil-market-based securities. A similar purpose is followed in Deaves and Krinsky (1992), Wirl and Kujundzic (2004), Guidi et al. (2006), and Hyndman (2008) among others, as well as studies including other OPEC issues such as reserves (Taylor and van Doren, 2005, and Considine, 2006). The results achieve certain consensus when quotas are reduced and oil prices are then increased, but this influence has declined since mid-1980s. This finding is in line with the evidence suggesting OPEC as a strong price setter during the 1970s.

OPEC's effective power has been analysed thoroughly from an economic point of view by researchers and policy makers (Pindyck, 1978; Salant, 1976; Teece, 1982; Moran, 1982; Hochman and Zilberman, 2015). Many diverse events have occurred since OPEC's establishment-mainly wars and other political instability realisations-and there is no consensus about the role of OPEC as price setter after the 1980s (Loderer, 1985; Smith, 2005; Fattouh, 2005). Most remarkably, Almoguera et al. (2011) suggest that the ability of OPEC to set prices since its creation is rather episodic. The authors find that during the period from 1974 until 2004, OPEC acted similar to a Cournot competition when sharing the global market with non-OPEC oil producers. Their empirical results, as the authors argue, are in favour of specific but non-time-robust price rises due to OPEC's comparison to the price level under competition. ${ }^{5}$

The extent to which OPEC sets prices and the effects of non-market externalities in oil spot prices are questionable. It is also questionable if oil price forecasters are aware or affected by these externalities when making their predictions. This is important because major oil supply disruptions bring attached detrimental effects of large unexpected shocks affecting stock indices (Hammoudeh and Eleisa, 2004; Hammoudeh and Li, 2004; Pollet, 2005; Malik and Hammoudeh, 2007; Driesprong et al., 2008; Balcilar et al., 2015) and even leading to recessions (Hamilton, 2003, 2009). Oil prices also carry a substantial amount of information to other prices affecting global inflation (see De Gregorio et al., 2007, Neely and Rapach, 2011, and Medel, 2015, 2016 for details).

Besides the impact on the level, comprehensive literature also analyses the impact of OPEC news on oil price volatility. Some examples are Deaves and Krinsky (1992), Horan et al. (2004), Fattouh (2005), Lin and Tamvakis (2010), Aguiar-Conraria and Wen (2012), Cairns and Calfucura (2012), Brémond et al. (2012), López and Muñoz (2012), Schmidbauer and Rösch (2012), and Mensi et al. (2014) among others.

It is a less clear-cut if just OPEC-related news is the only driver of oil price shocks, or if it is necessary to include a wider spectrum of supply disruptions such

5 The OPEC's behaviour analysed plainly as a cartel is also a long-standing issue in the literature. See, for instance, Adelman (1982), Aperjis (1982), Teece (1982), Dahl and Yücel (1989), Gülen (1996), Alhajji and Huettner (2000), Adelman (2002), and Fattouh (2007) among others. As above mentioned, the results are episodic and dependant on several assumptions previously made regarding OPEC's held power. 
as political instability, wars, or any news due to non-market externalities as well as news on alleviating oil supply. This is important because certain OPEC countries have been subject to substantial geopolitical risks and tensions not necessarily affecting the organisation's members countries only. For this reason, a key feature of this article is considering OPEC as one of many other oil-market-based news-generator devices for both oil supply contractions and expansions.

\section{ECONOMETRIC SETUP}

\subsection{Granger causality}

The notion of Granger causality is as simple as it is useful, and different from ordinary causality. It states that if lagged values of a variable $x_{t}$ predict current values of another variable $y_{t}$, and that forecast of $y_{t}$ includes lags of $x_{t}$ as well as $y_{t}$, then $x_{t}$ Granger cause $y_{t}$ (short notation: $x_{t} \rightarrow y_{t}$ ). In this article, we make use of the Hsiao (1981) version of Granger causality, extending it to a joint significance F-test of a whole set of parameters associated with the independent variable $\left(x_{t}\right)$ that cause the dependent variable $\left(y_{t}\right)$. Formally, this corresponds to testing if all the lags of $x_{t}$ are jointly statistically different from zero in the following regression:

$$
y_{t}=\mu+\sum_{i=1}^{p_{y}} \phi_{i} y_{t-i}+\sum_{j=1}^{p_{x}} \theta_{j} x_{t-j}+\varepsilon_{t},
$$

where lags of $y_{t}$ control for autocorrelation, $\left\{\mu ; \phi ; \theta ; \sigma_{\varepsilon}^{2}\right\}$ are parameters to be estimated with, say, ordinary least squares, assuming $\varepsilon_{t} \sim \operatorname{iidN}\left(0, \sigma_{\varepsilon}^{2}\right)$. The autoregressive orders $\left(p_{y}, p_{x}\right)$ in equation (1) vary from one to six lags to control for autocorrelation $\left(p_{y}\right)$ and to extend the Granger causality hypothesis testing $\left(p_{x}\right)$.

Statistical inference is carried out by testing the joint null hypothesis $N H: \theta_{1}=\ldots=\theta_{p x}=0\left(x_{t}\right.$ do not Granger cause $\left.y_{t} ; x_{t} \nrightarrow y_{t}\right)$. The vector that contains the restrictions is F-distributed with $\left(p_{x}, T-\left(p_{y}+p_{x}+1\right)\right)$ degrees of freedom (where $T$ is the sample size). A formal treatment can be found in Harvey $(\S 8.7,1990)$, Hamilton $(\$ 11.2,1994)$, and Patterson $(\$ 8.5,2000)$.

Notice that this inference is possible to make only if the coefficients are unbiased. In order to check for this statistical requirement, we provide the results of the BreuschGodfrey test for residuals' autocorrelation (Breusch, 1978; Godfrey, 1978). The suitability of this test relies on its ability to deal with nonstochastic regressors, such as the lagged values of the dependent variable, and testing higher-order autoregressive schemes, such as $A R(p)$, with $p>1$. The test is built-into a Lagrange multiplier test and proceeds as follows. The regression test assumes that residuals in equation (1) $\varepsilon_{t}$ follow a $p$-th autoregressive process and including the information of the independent 
variables of equation (1) (labelled as $\mathbf{X}_{t}$, and $\boldsymbol{\beta}$ is the vector of parameters of equation (1)):

$$
\varepsilon_{t}=\bar{\varepsilon}+\mathbf{X}_{t}^{\prime} \boldsymbol{\beta}+\rho_{1} \varepsilon_{t-1}+\ldots+\rho_{p} \varepsilon_{t-p}+v_{t}
$$

where $v_{t}$ is a white noise residual. The Breusch-Godfrey null hypothesis to be tested is that $\mathrm{NH}: \rho_{1}=\ldots=\rho_{p}$, that is, there is no serial correlation up to order $p$. We perform the test by setting this $p$-order up to six lags. Breusch (1978) and Godfrey (1978) have shown that $(T-p) R_{\varepsilon}^{2}$ is chi-squared distributed with $p$ degrees of freedom, where $R_{\varepsilon}^{2}$ is the goodness-of-fit coefficient of equation (2). Thus, if the $p$-value exceeds a chosen level of significance, we do not reject the null hypothesis, meaning that all $\rho_{1}=\ldots=\rho_{p}$ coefficients are zero, and no evidence of serial correlation is found.

\subsection{Short-sample bias}

Our analysis relies essentially on econometric estimations considering our geopolitical tensions and news variable which is available from 2001.1 to 2012.3 (135 observations) in monthly frequency. This fact could imply a short-sample bias and could invalidate the statistical inference obtained from coefficient estimates, i.e. the F-tests. Moreover, despite that all series used in estimations are stationary (as we test in subsection 3.4), they show a high level of persistence. Thus, this poses the risk of autocorrelated residuals; invalidating the inference based on F-tests.

To alleviate these problems, we make use of the Newey and West (1987) standard deviation estimator, which accounts for both heteroskedasticity and serial correlation. By setting key parameters -that will be shown below-, we will be able to use the Newey-West estimator to alleviate short-sample bias too. This is because the estimator corrects the off-diagonal elements of coefficients' variance(-covariance) matrix as well as heteroskedasticity. Thus, this correction goes beyond the case where the variance matrix $\Omega$ is different from $\sigma_{2} \mathbf{I}$. The estimator consists in an extension to White (1980)'s variance estimator when the problem is heteroskedasticity of a general unknown form.

The baseline ordinary least squares variance matrix corresponds to:

$$
\mathbb{E}\left[\mathbf{X}^{\prime} \boldsymbol{\varepsilon} \boldsymbol{\varepsilon}^{\prime} \mathbf{X} \mid \mathbf{X}\right]=\mathbf{X}^{\prime} \mathbf{\Omega} \mathbf{X}
$$

with $\boldsymbol{\Omega}$ being of unknown form. To materialise how the Newey-West estimator operates, consider the case of $T=4$ and $k=3$ (a constant plus two variables). In this case, we have that:

$$
\mathbf{X}^{\prime} \mathbf{\Omega} \mathbf{X}=\left[\begin{array}{cccc}
\mathbf{1} & \mathbf{1} & \mathbf{1} & \mathbf{1} \\
x_{12} & x_{22} & x_{32} & x_{42} \\
x_{13} & x_{23} & x_{33} & x_{43}
\end{array}\right]\left[\begin{array}{llll}
\sigma_{11} & \sigma_{12} & \sigma_{13} & \sigma_{14} \\
\sigma_{21} & \sigma_{22} & \sigma_{23} & \sigma_{24} \\
\sigma_{31} & \sigma_{32} & \sigma_{33} & \sigma_{34} \\
\sigma_{41} & \sigma_{42} & \sigma_{43} & \sigma_{44}
\end{array}\right]\left[\begin{array}{ccc}
\mathbf{1} & x_{12} & x_{13} \\
\mathbf{1} & x_{22} & x_{23} \\
\mathbf{1} & x_{32} & x_{33} \\
\mathbf{1} & x_{42} & x_{43}
\end{array}\right]=\sum_{t=1}^{T} \sum_{s=1}^{T} \sigma_{t s} \mathbf{X}_{t}^{\prime} \mathbf{X}_{s}
$$


where $\mathbf{X}_{s}=\left(\begin{array}{lll}\mathbf{1} & \mathbf{X}_{s 2} & \mathbf{X}_{s 3}\end{array}\right)$. The shape of equation (4) implies that $\sigma_{t s}$ provide weights associated with observations that differs in $t-s$ periods. If $\sigma_{t s}=0$ for $t \neq s$, there is no serial correlation of an order greater than " $s$ ".

Define $h \equiv t-s$, so, $s \equiv t-h$ and $\sigma_{t, h-t}=\sigma_{h-t, t}$, meaning that what matters for the correlation control is the time difference $h$. For example, if $\varepsilon_{t}$ are generated by a MA(2) process, all terms for which $|h|>2$ must be zero. The Newey-West estimator operates here in three ways. First, $\sigma_{t s}$ is replaced by $\varepsilon_{t} \varepsilon_{s}$ where $s=t-h$ and $\varepsilon_{t}$ are the residuals obtained with ordinary least squares. Second, the issue of how many autocovariances to include is latent. To determine this bandwidth, assume that $\varepsilon_{t}$ follows an $\operatorname{MA}(\mathcal{L})$ process, and so, the autocovariances to include should not exceed $\mathcal{L}$. Considering the frequency of our series, we set our baseline estimates with a bandwidth of six in oil price series (to control for possible seasonality), and one for the geopolitical risk measures. Finally, the Newey-West estimator introduces the weights $w_{h}$ on the products $\hat{\varepsilon}_{t} \hat{\varepsilon}_{s}$, with $s=t-h$, ensuring that the variance matrix is positive definite. These weights are calculated using the Bartlett window, and are of the shape $w_{h}=1-[h /(\mathcal{L}+1)]$ for $h=1, \ldots, \mathcal{L}$. Thus, the weights decline from $\mathcal{L} /(\mathcal{L}+1)$ to $1 /(\mathcal{L}+1)$. With these three considerations, the Newey-West estimator of $\left[\mathbf{X}^{\prime} \boldsymbol{\varepsilon} \boldsymbol{\varepsilon}^{\prime} \mathbf{X} \mid \mathbf{X}\right]$ is:

$$
\boldsymbol{\Xi}=\sum_{\text {heteroskedasticity ad justment }}^{\sum_{t=1}^{T} \varepsilon_{t}^{2} \mathbf{X}_{t}^{\prime} \mathbf{X}_{t}}+\underbrace{\sum_{h=1}^{\mathcal{L}} \sum_{t=h+1}^{T} w_{h} \hat{\varepsilon}_{t} \hat{\varepsilon}_{t-h}\left(\mathbf{X}_{t}^{\prime} \mathbf{X}_{t-h}+\mathbf{X}_{t-h}^{\prime} \mathbf{X}_{t}\right)}_{\text {serial correlation adjustment }},
$$

and, thus, the Newey-West estimator of the variance matrix $\left(\mathbf{X}^{\prime} \mathbf{X}\right)^{-1} \mathbf{X}^{\prime} \mathbf{\Omega} \mathbf{X}\left(\mathbf{X}^{\prime} \mathbf{X}\right)^{-1}$ of $\hat{\beta}$ is:

$$
\mathbb{V}^{\text {Newey-West }}[\hat{\beta}]=\left(\mathbf{X}^{\prime} \mathbf{X}\right)^{-1} \mathbf{E}\left(\mathbf{X}^{\prime} \mathbf{X}\right)^{-1},
$$

and the estimator is said heteroskedasticity and autocorrelation consistent.

For robustness purposes, we also conduct the full exercise making use of the jackknife estimator of coefficients standard deviation. The jackknife first-order unbiased estimator serves primarily in cases where some observations could be influencing the overall statistic. The estimator repeatedly calculates the standard deviation each time omitting just one of the dataset's observations. If $y_{i}$ is the $i$-th observation of the data with $i=1, \ldots, T$, the jackknife estimator of the standard deviation makes use of the mean:

$$
\bar{y}=\frac{(T-1) \bar{y}_{(i)}+y_{i}}{T},
$$

where $\bar{y}_{(i)}$ is the mean using the entire sample excluding the $i$-th observation. Thus, solving for $y_{i}$ we have: 


$$
y_{i}=T \bar{y}+(T-1) \bar{y}_{(i)}
$$

and more generally:

$$
\hat{\theta}_{i}^{*}=T \hat{\theta}+(T-1) \hat{\theta}_{(i)}
$$

These are the pseudovalues that configure the jackknife estimator, corresponding to the mean of those pseudovalues with a standard deviation equivalent to the standard deviation calculated for $\hat{\theta}$ (Tukey, 1958):

$$
\mathbb{V}^{\text {Jackknife }}[\hat{\beta}]=\left[\frac{T-1}{T}\right] \sum_{i=1}^{T}\left(\hat{\theta}_{(i)}-\overline{\hat{\theta}}\right)^{2}
$$

As is possible noticing, the jackknife estimator is a valid alternative dealing with heteroskedasticity and the over-representation that few observations could have in a short-sample environment; but not necessarily dealing better than the Newey-West estimator under serial correlation. For this reason, our baseline estimates are based on the Newey-West estimator, whereas jackknife-based results are available for robustness only.

\subsection{An application to the oil market}

We label our measure of geopolitical tensions and news as "GT\&N" which is constructed, as mentioned above, as the sum of 10 dummy variables related to the oil market. Adding specific 9 out of 10 non-OPEC related variables we generate the "GT\&N-NO" variable, while the remaining dummy concerning purely OPEC is labelled

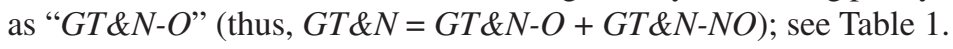

By means of Granger causality we provide evidence on the following hypotheses:

- H1: Do $G T \& N$ cause the Brent oil price $\left(P^{O i l}\right): G T \& N \rightarrow P^{O i l}$ ?

- H2: Do $G T \& N$ cause oil price forecasts ( $\left.\mathbb{E}\left[P^{\text {oil }}\right]\right): G T \& N \rightarrow \mathbb{E}\left[P^{o i l}\right]$ ? and

- H3: Do $G T \& N$ affect the dispersion of oil price forecasts $\left(\mathbb{D}\left[P^{\text {oil }}\right]\right): G T \& N \rightarrow \mathbb{D}\left[P^{\text {oil }}\right]$ ?

In order to conclude about the reliability of the $G T \& N$ variable, it is expected that all these hypotheses must have statistical significance in the shown direction. At the same time, a unidirectional relationship is expected in $H 1$, with $G T \& N$ causing $P^{O i l}$ but not the other way around. This is merely to ensure that $G T \& N$ is exogenous and is actually measuring unexpected news. 
If oil price expectations are orthogonal to oil producers' information set, it should follow that $\mathbb{E}\left[P^{\text {oil }}\right] \nrightarrow G T \& N$. Also, greater tensions are associated with uncertainty about future oil prices. For that reason, it is expected that $G T \& N \rightarrow \mathbb{D}\left[P^{\text {oil }}\right]$, and the inverse should not hold; again, if the $G T \& N$ is exogenous and measuring unexpected news. ${ }^{6}$

Our analysis involves oil price forecasts for two reasons. The first one is the true interest in investigating to which extent both forecast level and dispersion are affected by the $G T \& N$ variable. The second reason is to stress out the reliability of the newly proposed $G T \& N$ measure and its components.

The analysis continues by testing the same set of three hypotheses making use of the $G T \& N-O$ and $G T \& N-N O$ variables. Notice that given the geographical proximity of the majority of considered oil-producer countries, it is difficult to fully isolate both measures and some intertemporal interaction may exist in specific events. However, we do not impose an orthogonality condition between them, opting for preserving the benefit of simplicity and easy-to-read results.

\subsection{Dataset}

The analysis is made considering a time window spanning from 2001.1 until 2012.3 in monthly frequency, comprising 135 observations. Notice that the $G T \& N$ variable is available as from 1999. So, the limiting part of the analysis are the oil price forecasts, starting in 2001. The $G T \& N$ variable is constructed by adding 10 categorical dummy variables, in which the value of one is assigned to an unexpected event (geopolitical tension or news) associated to an oil supply expansion, minus one to an oil supply contraction, and zero otherwise. There is one category fully deserved for OPEC events while the remaining belong to non-OPEC countries.

A total of 204 events are identified across the 10 categories listed in Table 1. More detailed descriptions on the type of events are included in each category that can be found in Appendix A as well as the time-series graph of the $G T \& N$ variable in Figure A1. For a daily individual-level identification, see Appendix A of López and Muñoz (2012). The sources of geopolitical tensions and news are Bloomberg, The Wall Street Journal, Financial Times, and the United States Energy Information Administration and are manually coded comprehensively according to informational content. The $G T \& N$ variable is not recoded to, for instance $(-1,0,1)$ after adding its components, to preserve its intensity.

6 Notice that Bowles et al. (2007) and Atallah et al. (2013) proposed a similar methodology when measuring disagreement among the European Central Bank's surveys' respondents. 


\section{TABLE 1}

GEOPOLITICAL TENSIONS AND NEWS: COMPONENTS AND DESCRIPTION (*)

\begin{tabular}{|c|l|c|c|c|}
\hline $\mathrm{N}^{\mathbf{0}}$ & \multicolumn{1}{|c|}{ Description } & Classification & $\begin{array}{c}\text { Supply } \\
\text { effect }\end{array}$ & $\begin{array}{c}\mathrm{N}^{\mathbf{o}} \\
\text { events }\end{array}$ \\
\hline 1 & United Nations Oil for Food Program (1995-2003) & Non OPEC & $(+)$ & 14 \\
2 & United States relations with Libya and Iran (1996-2004) & Non OPEC & $(-)$ & 6 \\
3 & Iraq War and post-war period (2003-2011) & Non OPEC & $(-)$ & 26 \\
4 & Iran post Iraq War (start in 2005) & Non OPEC & $(-)$ & 10 \\
5 & Terrorist attacks & Non OPEC & $(-)$ & 22 \\
6 & Lebanon War (2006) & Non OPEC & $(-)$ & 8 \\
7 & Arab Spring (2011) & Non OPEC & $(-)$ & 25 \\
8 & Use of the United States Strategic Petroleum Reserve & Non OPEC & $(+)$ & 3 \\
9 & New announcements on discoveries, and site exploration & OPEC & $(+)$ & 17 \\
10 & Purely OPEC announcements & & 73 \\
\hline
\end{tabular}

(*) Total events: 204 (sample: 2001.1-2012.3).

Source: Authors' calculations.

Actual oil price means to the annual percentage change of the Brent oil price measured in USD per barrel (source: Bloomberg; $P^{\text {Oil }}=100 \times\left(\left(\right.\right.$ Oil price $_{t} /$ Oil price $\left._{t-12}\right)$ 1). Oil price forecasts corresponds to the annual percentage change of the 12 months ahead forecast contained in the monthly Consensus Forecast (CF) report, but using the actual value as denominator $\left(\mathbb{E}\left[P^{\text {oil }}\right]=100 \times\left(\right.\right.$ Oil price forecast $_{t} /$ Oil price $\left.\left.\left._{t-12}\right)-1\right)\right)$. The point estimator displayed in $\mathrm{CF}$ report corresponds to the mean of the answers at the same horizon, ranging 65-70 respondents. Each report also shows the maximum and the minimum point value answered by respondents; $\mathbb{E}_{12}\left[P^{\text {oil }}\right]=$ oil price forecast ${ }^{\text {High }}$ and $\mathbb{E}_{12}\left[P^{\text {oil }}\right]=$ oil price forecast ${ }^{\text {Low }}$, respectively and $\mathbb{E}_{12}$ is the forecast 12 -monthsahead. Hence, the difference $\mathbb{D}\left[P^{\text {Oil }}\right]=\left[\right.$ oil price forecast ${ }^{\text {High }}$ - oil price forecast $\left.{ }^{\text {Low }}\right]$, measures the dispersion or, in other words, the degree to which the consensus is achieved in forming oil price forecasts; the greater the uncertainty, the smaller the consensus achieved.

Figure 1 exhibits the time series of actual oil prices, and $\mathrm{CF}$ expectations and dispersion. Notice that exogenous to all of these variables, including $G T \& N$, there is a noticeable impact of the 2008-09 Global Financial Crisis initiated after the bankruptcy of Lehmann Brothers investment bank in the United States. As shown in Figure A1, we notice a number of disturbances during 2001 (due to the 9/11 terrorist attacks), 2003 (Iraq War), mid-2005 (Lebanon War), and the 2011-12 period (Arab Spring). Table 2 presents the descriptive statistics of all involved series using the transformation that achieves stationarity according to the Augmented Dickey-Fuller (ADF), Kwiatkowski, Phillips, Schmidt, and Shin (KPSS), and Phillips-Perron (PP) tests. 


\section{FIGURE 1}

BRENT OIL PRICE, OIL PRICE FORECASTS AND DISPERSION (*)

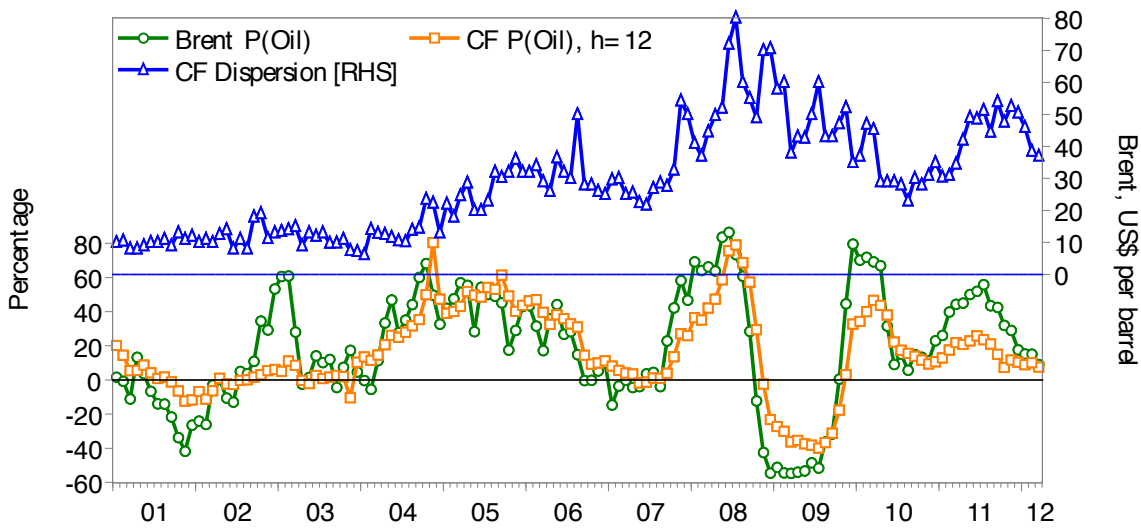

(*) Source: Authors' elaboration using data from Bloomberg, Consensus Forecast, and López and Muñoz (2012).

TABLE 2

DESCRIPTIVE STATISTICS OF THE TIME SERIES (*)

\begin{tabular}{|l|c|c|c|c|c|c|}
\cline { 2 - 7 } \multicolumn{1}{c|}{} & $P^{\text {Oil }}$ & $E\left[P^{\text {Oil }}\right]$ & $D\left[P^{\text {Oil }}\right]$ & $G T \& N$ & $G T \& N-O$ & $G T \& N-N O$ \\
\hline Transformation & Ann. perc. & Ann. perc. & US\$/barrel & $\mathrm{N}^{\circ}$ events & $\mathrm{N}^{\circ}$ events & $\mathrm{N}^{\circ}$ events \\
\hline Mean & 18.84 & -4.95 & 27.65 & -0.69 & -0.27 & -0.43 \\
Median & 17.28 & -8.26 & 26.00 & 0 & 0 & 0 \\
Maximum & 86.55 & 44.82 & 80.16 & 4 & 3 & 2 \\
Minimum & -54.65 & -23.53 & -1.40 & -13 & -3 & -10 \\
Std. deviation & 33.66 & 12.87 & 17.05 & 1.81 & 0.87 & 1.54 \\
ADF Statistic & -3.44 & -3.55 & -3.50 & -9.08 & -4.35 & -7.91 \\
$\quad p$-value & 0.01 & 0.01 & 0.04 & 0.00 & 0.00 & 0.00 \\
KPSS Statistic & 1.99 & 4.11 & 2.04 & 0.28 & 1.89 & 0.62 \\
$p$-value & 0.35 & 0.35 & 0.12 & 0.35 & 0.35 & 0.35 \\
PP Statistic & -3.47 & -3.55 & -3.84 & -9.01 & -13.02 & -7.91 \\
$\quad p$-value & 0.01 & 0.01 & 0.02 & 0.00 & 0.00 & 0.00 \\
\hline
\end{tabular}

(*) Sample: 2001.1-2012.3 (135 obs.). “ADF” stands for Augmented Dickey-Fuller test (NH: the series has a unit root). "KPSS" stands for the Kwiatkowski, Phillips, Schmidt, and Shin test (NH: the series is stationary). "PP" stands for the Phillips and Perron test (NH: the series has a unit root). All test regressions include a constant and a lag length criterion based on the Bayesian Information Criterion searching in a maximum of 12 lags, except $\mathbb{D}\left[P^{\text {oil }}\right]$ that includes a trend and one (fixed) lag.

Source: Authors' elaboration using data from Bloomberg, Consensus Forecast, and López and Muñoz (2012). 


\section{RESULTS}

The results using the $G T \& N$ variable are reported in Table 3 . In the first panel, $\mathrm{H} 1$ shows that from the third up to the sixth lag, $G T \& N$ cause oil price at $5 \%$ significance level. This implies that geopolitical tensions and news take at least three months to affect Brent oil prices. Given the relevance of oil to both producers and buyers, the market works with forward contracts to reduce the uncertainty surrounding final prices and just a portion of deals are closed at spot prices. This is relevant to understand the short lag in which $G T \& N$ affect oil prices and the apparent disconnection between these two variables. These results are supported by the Breusch-Godfrey test showing no serial correlation. The H1 Inverse hypothesis, in turn, rejects the hypothesis of a feedback relationship between $G T \& N$ and oil price, confirming the unidirectional effect of $G T \& N$ causing oil price.

The two-month lag with which $G T \& N$ operates over the oil price disappears when considering the results of the second panel, where $G T \& N$ cause oil price expectations for all lags except the second. This implies that forecasters already consider geopolitical tensions and news when forming their expectations about oil prices. Notice also that we are considering 12-month-ahead forecasts, and thus, tensions and news that are affecting forecasts more permanently than immediate and short-term shocks. The Breusch-Godfrey test finds no serial correlation at the $10 \%$ level of significance. Finally, the $\mathrm{H} 2$ Inverse hypothesis comes out as statistically non significant, confirming that the oil producers' tensions and news are exogenous to forecasters' information set and our measure is actually capturing unexpected events.

The third panel shows that for lags one and four evidence is found favouring geopolitical tensions and news affecting forecast dispersion. This implies that the way in which forecasters treat the information contained in the $G T \& N$ variable differs, resulting in different implications to the oil price. Same as above, no serial correlation is found with the Breusch-Godfrey test. Regarding the H3 Inverse hypothesis, two cases of statistical significance are found, with three and six lags, and residuals tests do not reject no-autocorrelation. This result implies a feedback relationship between the variables. However, this is a priori likely the case when considering that $G T \& N$ cause disagreement; thus, lagged disagreement operates over the inertial component of $G T \& N$.

In sum, Table 3 provides the statistical evidence in the direction proposed in subsection 3.3. The same kind of results is, thus, obtained by distinguishing between OPEC and non-OPEC geopolitical tensions and news.

The results using the purely OPEC measure of geopolitical tensions and news are presented in Table 4. The first panel shows that purely OPEC-based does not Granger cause current oil price, a result supported by the Breusch-Godfrey test. In turn, when analysing the H1 Inverse hypothesis, we find that oil price cause OPEC's geopolitical tensions and news, particularly between the second and fourth months. This imply that OPEC is actually sensitive to movements in oil prices and the causality goes in 


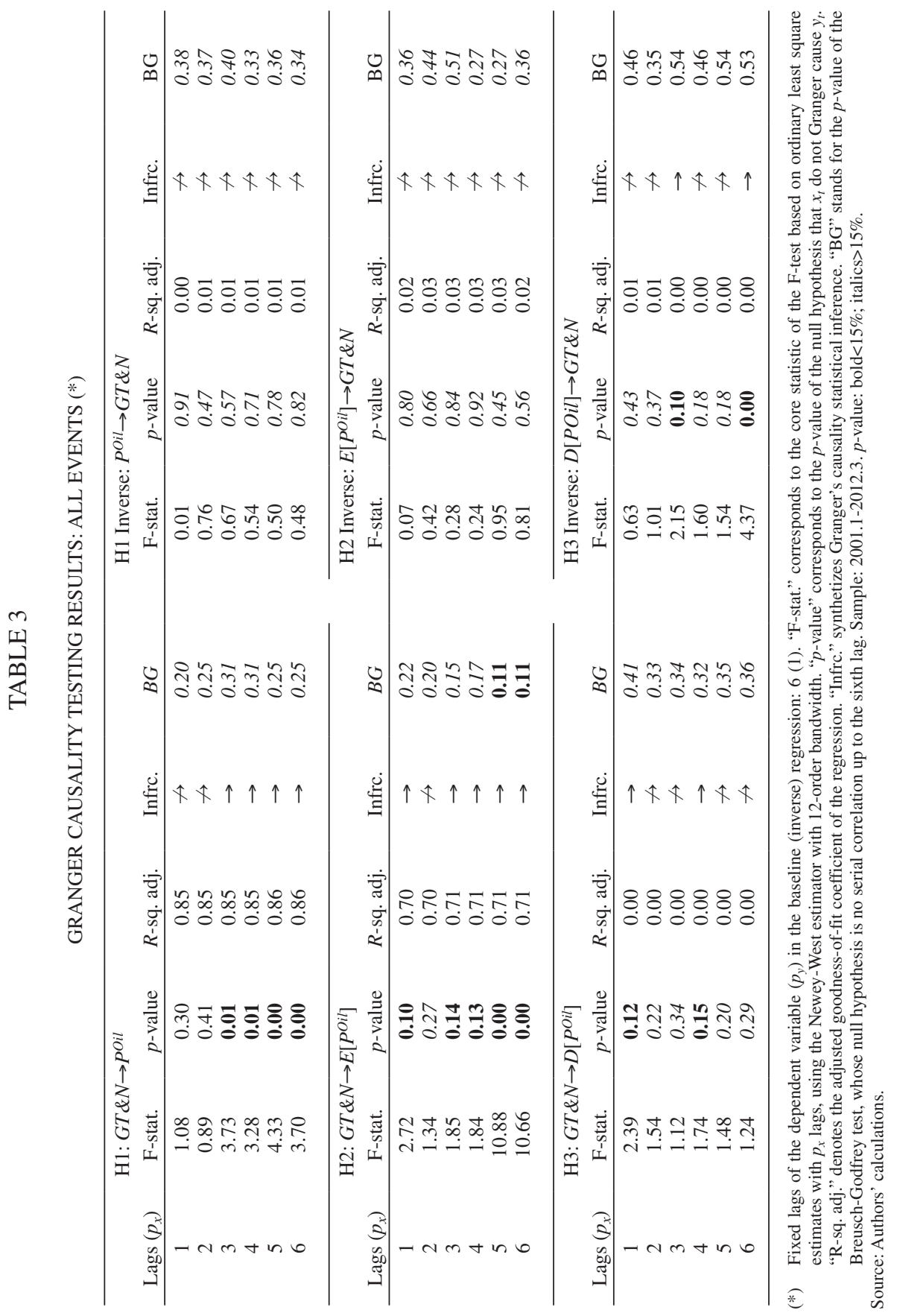


this direction only. As our geopolitical tensions and news measure include quotas reassignments as well as major maintenances, OPEC could react to oil prices with a lag but not necessarily neither affecting nor determining future oil price dynamics.

Similar to the case when considering all geopolitical events, the second panel of Table 4 provides evidence supporting the hypothesis of $G T \& N-O$ causing oil price forecasts (for the fifth and sixth lags), supported with the results of the Breusch-Godfrey test. Also, the causality goes in this direction only, and not oil price forecasts causing OPEC's news. This result is not necessarily surprising given the relevance of OPEC for the oil market, and thus, analysts consider its news when making its forecasts.

The third panel of Table 4, in turn, shows a feedback relationship between OPEC news and oil price forecasts' dispersion. This means that OPEC news cause forecasters' dispersion and, at the same time, uncertainty in future oil prices leads to news in OPEC countries-similarly to future oil prices. These results also support the claim that OPEC reacts to the uncertainty about oil price forecasts, but not necessarily affecting its realised level.

In sum, Table 4 provides evidence supporting OPEC playing a role in oil price expectations formation's both level and dispersion, but not ultimately determining the current spot oil price. Moreover, OPEC seems to react to actual oil prices as well as in volatility episodes represented by a major disagreement in oil price forecasts.

The results using the non-OPEC measure of geopolitical tensions and news are presented in Table 5. Overall, the results are qualitatively similar to the case that considers all geopolitical tensions and news (Table 3). The first panel of Table 5 virtually mimics the corresponding one in Table 3 . This means that for $\mathrm{H} 1$ it is shown that from the third lag up to sixth, GT\&N-NO cause oil price at 5\% significance level, implying that non-OPEC geopolitical tensions and news take the same three months to affect Brent oil prices. The results are supported by the Breusch-Godfrey test and statistically non-significant results when testing the causality in the opposite direction. This finding also reinforces the hypothesis that OPEC by itself does not directly affect the oil price, but rather its forecasts level and dispersion.

Similarly, the second panel of Table 5 shows that the non-OPEC geopolitical tensions cause oil price expectations from the third lag onwards (but the fourth lag autocorrelated), implying that future oil prices are formed not only by OPEC news, but also by geopolitical tensions in general. This result is supported with the causality going in this direction only. The third panel, in turn, shows that non-OPEC news cause forecast disagreement with the first lag only. Recall that when using the measure with all tensions and news, this occurs with the first and fourth lags, while with the OPEC measure, from the fourth lag onwards. This means that there are tensions and nonOPEC news that immediately affect forecasters' consensus, or that at the same time, and given its more diverse nature, it is information that is more difficult to process by forecasters making it difficult to achieve a consensus.

In summary, geopolitical tensions and news in general affect the current oil price as well as its forecasts and dispersion. When distinguishing between news and tensions 


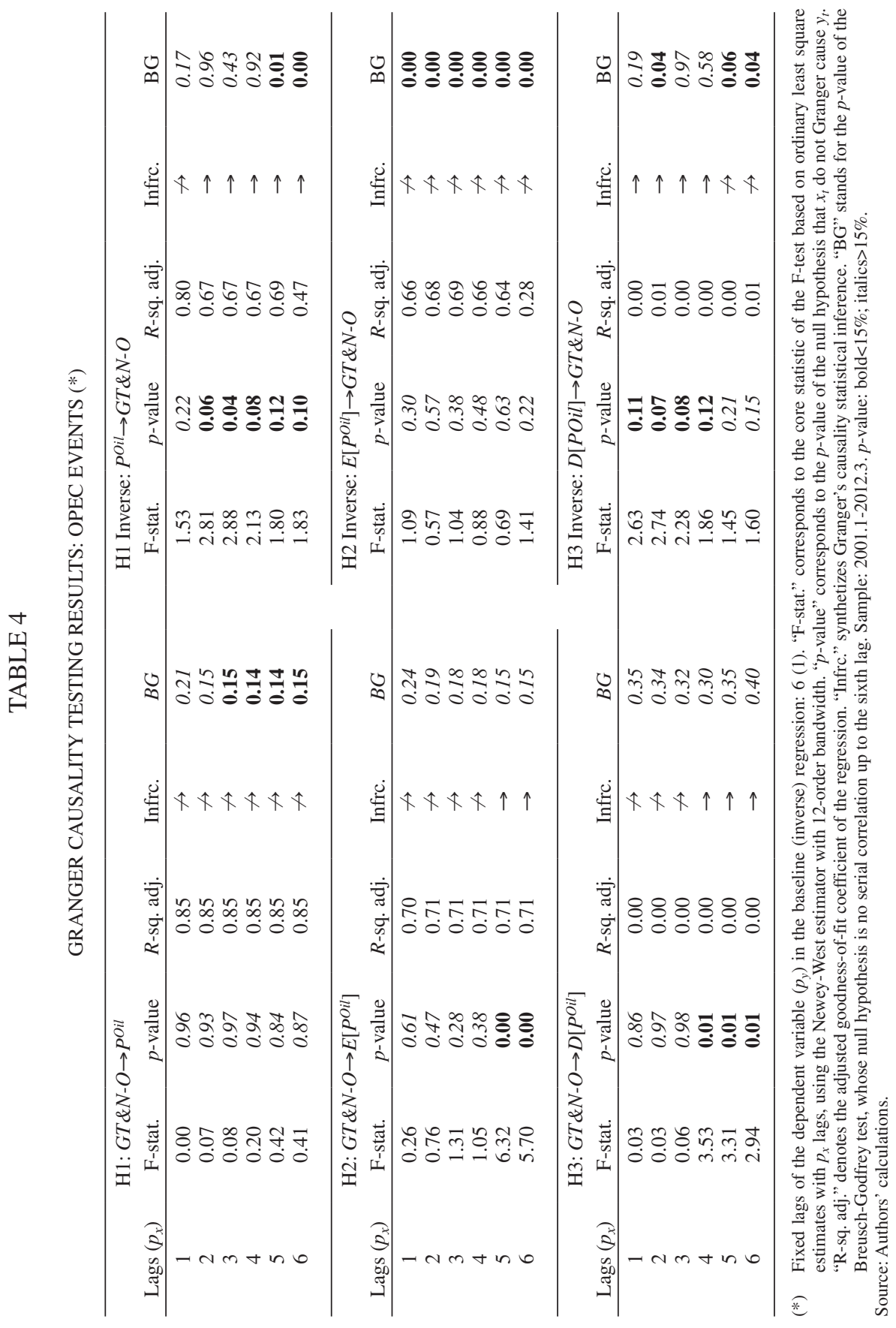




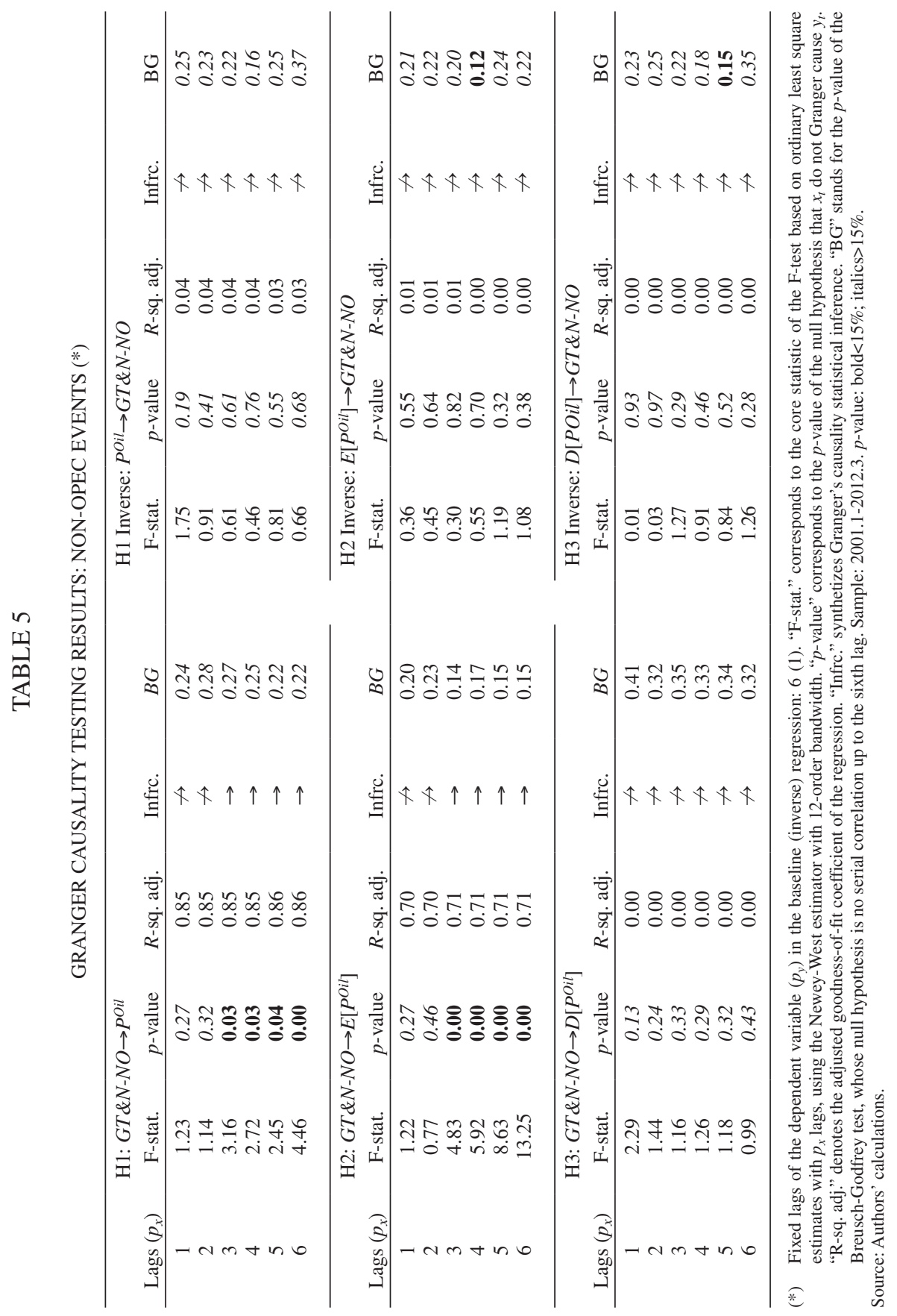


from OPEC versus non-OPEC, we find that the latter affects the spot oil price and, at the same time, oil prices cause the news related to the oil supply in OPEC countries (without affecting the spot price). Both measures of geopolitical tensions and news cause oil price forecasts starting from the three-month horizon. Additionally, both measures cause the dispersion around these forecasts, although the most immediate effect is due to tensions and news unrelated to OPEC.

\section{SUMMARY AND CONCLUDING REMARKS}

Crude oil and its processed liquids are essential commodities for the world economy. The chronic oil dependence of major economies and a degree of geographic concentration of part of the biggest oil-producer countries which, at the same time, suffer of high political instability and uprisings, carry particular features to this global market. On top of that, it is added the existence of OPEC "to coordinate and unify policies of its member countries" (OPEC, 2012), leading to think about them acting as a cartel. It is relevant then to delve into the particular effect of (non-economic based) unexpected geopolitical tensions and news related to major oil producers, and disentangling the news related to OPEC on oil price within a wider environment of threats, tensions, political instability, and oil supply news.

In this article, we empirically test these hypotheses using a unique, purposely built media-based measure of geopolitical tensions and news accounting not only for supply crunches but also for expansions, comprising the 2001-12 period. Our measure is the result of adding (or subtracting) 10 dummy variables associated to news relevant to the oil market, as suggested by its sources (Bloomberg, The Wall Street Journal, Financial Times, and the United States Energy Information Administration). One of these dummy variables is exclusively referred to OPEC. To stress out the informational content of the newly proposed geopolitical tensions and OPEC news measure, we analyse its effect not only on current Brent oil price but also on its forecast and dispersion, as included in the Consensus Forecast survey.

By means of Granger causality, three hypotheses are examined and supported by testing the other way around to determine full independence or a feedback relationship between variables. The first hypothesis is if the overall (OPEC plus non-OPEC) geopolitical tensions and news measure Granger cause the current oil price. The second hypothesis is if the same measure cause oil price forecasts, and a third one if the same occur for forecast dispersion (consensus). We then perform these three hypotheses using the non-OPEC and purely OPEC measures to compare and conclude about what actually influence oil prices.

After stressing out our measure of geopolitical tensions and news, obtaining a reliable outcome, we found evidence suggesting that overall geopolitical tensions and news affect the current level of the oil price, its forecasts, and the dispersion of those forecasts. More remarkably, when distinguishing between OPEC versus non-OPEC 
news, we found that the former affect oil price forecasts and its consensus, and at the same time, the current oil price determines oil-based news on OPEC countries. Moreover, non-OPEC news affect the current and future oil price level and they are not affected by the current level and neither the forecast nor the dispersion of those forecasts.

All these results imply that geopolitical tensions and news in a broader sense affect oil prices, and OPEC news should be read jointly with other geopolitical tensions as oil price drivers -and not as an isolated news generator. This weakens the hypothesis of OPEC as a price setter in the global oil market whose behaviour, in turn, seems a matter for forecasters. Moreover, it is the current oil price that affects the OPEC-based news.

These results are important suggesting that, in order to keep track of oil price dynamics, is needed accounting for a more general context of news and geopolitical tensions beyond OPEC countries, relying on signals and externalities that are not necessarily based on economic rationale.

\section{DISCLOSURE}

No interest other than an economic research question on applied economics has motivated this article. There is no conflict of interests of any kind involved in the production of this article.

\section{REFERENCES}

ADELMAN, M.A. (1982). "OPEC as a Cartel”, in G.M. Griffin and D.J. Teece (Eds.), OPEC Behaviour and World Oil Prices, Allen \& Unwin, London, UK.

ADELMAN, M.A. (2002). "World Oil Production and Prices 1947-2000", Quarterly Review of Economics and Finance 42 (2), pp. 169-191.

AGUIAR-CONRARIA, L. and Y. WEN (2012). "OPEC's Oil Exporting Strategy and Macroeconomics (In)stability”, Energy Economics 34 (1), pp. 132-136.

ALHAJJI, A. and D. HUETTNER (2000). "OPEC and the World Oil Markets from 1973 to 1994: Cartel, Oligopoly or Competitive?" The Energy Journal 21 (3), pp. 31-60.

ALMOGUERA, P.A., C.C. DOUGLAS, and A.M. HERRERA (2011). "Testing for the Cartel in OPEC: Non-cooperative Collusion or just Non-cooperative?” Oxford Review of Economic Policy 27 (1), pp. 144-168.

ANTONANAKIS, N., I. CHATZIANTONIOU, and G. FILIS (2014). "Dynamic Spillovers of Oil Price Shocks and Economic Policy Uncertainty", Energy Economics 44, pp. 433-447.

ANTONANAKIS, N., R. GUPTA, C. KOLLIAS, and S. PAPADAMOU (2017). "Geopolitical Risks and the Oil-stock Nexus over 1899-2016", Finance Research Letters 23, pp. 165-173.

APERJIS, D. (1982). The Oil Market in the 1980s, OPEC Oil Policy and Economic Development, Ballinger Publishing Co., Cambridge, MA, US.

ATTALLAH, T., F. JOUTZ, and A. PIERRU (2013). "Does Disagreement Among Oil Price Forecasters Reflect Future Volatility? Evidence from the ECB Surveys", presentation prepared for Research Program 
on Forecasting Brown Bag Seminar, Department of Economics, George Washington University, 6 March, 2013.

BACHMANN, R., ELSTNER, S. and E. SIMS (2013). "Uncertainty and Economic Activity: Evidence from Business Survey Data", American Economic Journal: Macroeconomics 5 (2), pp. 217-249.

BALCILAR, M., R. GUPTA, and S.M. MILLER (2015). "Regime Switching Model of US Crude Oil and Stock Market Prices: 1859 to 2013", Energy Economics 49 (1), pp. 317-327.

BAKER, S.R., N. BLOOM, and S.J. DAVIS (2016). "Measuring Economic Policy Uncertainty", Quarterly Journal of Economics 131 (4), pp. 1593-1636.

BARRETT, A.B. and L. BARNETT (2013). "Granger Causality is Designed to Measure Effect, Not Mechanism", Frontiers in Neuroinformatics 7, Article 6.

BEKIROS, S., R. GUPTA, and A. PACCAGNINI (2015). "Oil Price Forecastability and Economic Uncertainty", Economic Letters 132, pp. 125-128.

BHOLAT, D., S. HANSEN, P. SANTOS, and C. SCHONHARDT-BAILEY (2015). "Text Mining for Central Banks", Centre for Central Banking Studies, Bank of England.

BLOOM, N. (2009). "The Impact of Uncertainty Shocks", Econometrica 77 (3), pp. 623-685.

BOWLES, C., R. FRIZ, V. GENRE, G. KENNY, A. MEYLER, and T. RAUTANEN (2007). "The ECB Survey of Prefessional Forecasters: A Review after Eight Years Experience", Occasional Paper 58, European Central Bank.

BREMOND, V., E. HACHE, and V. MIGNON (2012). "Does OPEC Still Exists as a Cartel? An Empirical Investigation", Energy Economics 34 (1), pp. 125-131.

BREUSCH, T.S. (1978). "Testing for Autocorrelation in Dynamic Linear Models", Econometrica 17, pp. 334-355.

BURGGRAF, T., R. FENDEL, and T.L.D. HUYNH (2019). "Political News and Stock Prices: Evidence from Trump's Trade War", forthcoming, Applied Economic Letters.

CAIRNS, R.D. and E. CALFUCURA (2012). “OPEC: Market Failure or Power Failure?” Energy Policy 50, pp. 570-580.

CALDARA, D. and M. IACOVIELLO (2018). "Measuring Geopolitical Risk", International Finance Discussion Papers, Board of Governors of the Federal Reserve Board.

CONSIDINE, T.J. (2006). "Is the Strategic Petroleum Reserve Our Ace in the Hole?" The Energy Journal 27 (3), pp. 91-112.

DAHL, C. and M. YÜCEL (1989). "Dynamic Modeling and Testing of OPEC Behaviour", Research Paper 8917, Federal Reserve Bank of Dallas.

DE GREGORIO, J., O. LANDERRETCHE, and C. NEILSON (2007). "Another Pass-Through Bites the Dust? Oil Prices and Inflation", Economia 7, pp. 155-196.

DEAVES, R. and I. KRINSKY (1992). "The Behaviour of Oil Futures Returns around OPEC Conferences", Journal of Future Markets 12 (5), pp. 563-574.

DEMIRER, R. and A.M. KUTAN (2010). "The Behaviour of Crude Oil Spot and Future Prices Around OPEC and SPR Announcements: An Event Study Perspective”, Energy Economics 32, pp. 1467-1476.

DRAKOS, K. and C. KALLANDRANIS (2015). "A Note on the Effect of Terrorism on Economic Sentiment", Defence and Peace Economics 26 (6), pp. 600-608.

DRAPER, D.W. (1984). "The Behaviour of Event-Related Returns on Oil Futures Contracts", Journal of Futures Markets 4, pp. 125-132.

DRIESPRONG, G., B. JACOBSEN, and M. BENJIMAN (2008). "Striking Oil: Another Puzzle?" Journal of Financial Economics 89 (2), pp. 307-327.

FATTOUH, B. (2005). “The Causes of Crude Oil Price Volatility”, Middle East Economic Survey XLVIII, pp. 13.

FATTOUH, B. (2007). "The Drivers of Oil Prices: The Usefulness and Limitations of Nonstructural Model, the Demand-Supply Framework and Informal Approaches", WPM 32, Oxford Institute for Energy Studies.

GAIBULLOEV, K. and T. SANDLER (2009). "The Impact of Terrorism and Conflicts on Growth in Asia", Economics \& Politics 21 (3), pp. 359-383. 
GODFREY, L.G. (1978). "Testing Against General Autoregressive and Moving Average Error Models when the Regressors include Lagged Dependant Variables", Econometrica 46, pp. 1293-1302.

GRANGER, C.W.J. (1969). "Investigating Causal Relations by Econometric Models and Cross-spectral Methods", Econometrica 37 (3), pp. 424-438.

GRANGER, C.W.J. (1980). "Testing for Causality: A Personal Viewpoint”, Journal of Economic Dynamics and Control 2, pp. 329-352.

GRANGER, C.W.J. (2004). "Time Series Analysis, Cointegration, and Applications”, American Economic Review 94 (3), pp. 421-425.

GRIFFIN, J.M. and D. TEECE (1982). OPEC Behaviour and World Oil Prices, Allen \& Unwin, London, UK.

GRIFFIN, J.M. and W. XIONG (1997). "The Incentive to Cheat: An Empirical Analysis of OPEC", Journal of Law and Economics 40, pp. 289-316.

GUIDI, M.G.D., A. RUSSELL, and H. TARBERT (2006). "The Effects of OPEC Policy Decisions on Oil and Stock Prices", OPEC Review 30, pp. 1-18.

GUIDOLIN, M. and E. LA FERRARA (2010). "The Economic Effects of Violent Conflict: Evidence from Asset Market Reactions", Journal of Peace Research 47 (6), pp. 671-684.

GÜLEN, S.G. (1996). "Is OPEC a Cartel? Evidence from Cointegration and Causality Tests", The Energy Journal 17 (2), pp. 43-57.

HAMILTON, J.D. (1994). Time Series Analysis, Princeton University Press, US.

HAMILTON, J.D. (2003). "What is an Oil Shock?" Journal of Econometrics 113 (2), pp. 363-398.

HAMILTON, J.D. (2009). "Causes and Consequences of the Oil Shock of 2007-2008", Brookings Papers on Economic Activity (Spring), pp. 215-261.

HAMMOUDEH, S. and E. ELEISA (2004). "Dynamic Relationships Among the GCC Stock Markets and the NYMEX Oil Prices", Contemporary Economic Policy 22 (2), pp. 250-269.

HAMMOUDEH, S. and H. LI (2004). "The Impact of the Asian Crisis on the Behaviour of US and International Petroleum Prices", Energy Economics 26 (1), pp. 135-160.

HARVEY, A.C. (1990). The Econometric Analysis of Time Series, Second Edition, Phillip Allan, UK.

HOCHMAN, G. and D. ZILBERMAN (2015). "The Political Economy of OPEC", Energy Economics 48, pp. 203-216.

HORAN, S.M., J.H. PETERSON, and J. MAHAR (2004). "Implied Volatility of Oil Futures Options Surrounding OPEC Meetings", The Energy Journal 25 (3), pp. 103-125.

HSIAO, C. (1981). "Autoregressive Modelling and Money-Income Causality Detection", Journal of Monetary Economics 7, pp. 85-106.

HYNDMAN, K. (2008). "Disagreement in Bargaining: An Empirical Analysis of OPEC", International Journal of Industrial Organisation 26, pp. 811-828.

JONES, C.T. (1990). "OPEC Behaviour under Falling Prices: Implications for Cartel Stability”, The Energy Journal 11 (3), pp. 117-129.

JOO, Y.C. and S.Y. PARK (2017). "Oil Prices and Stock Markets: Does the Effect of Uncertainty Change over Time?” Energy Economics 61, pp. 42-51.

JURADO, K., S. LUDVIGSON, and S. NG (2015). "Measuring Uncertainty", American Economic Review 105 (3), pp. 1177-1216.

KANG, W. and R.A. RATTI (2013a). "Oil Shocks, Policy Uncertainty and Stock Market Return”, Journal of International Financial Markets, Institutions and Money 26, pp. 305-318.

KANG, W. and R.A. RATTI (2013b). "Structural Oil Price Shocks and Policy Uncertainty", Economic Modelling 35, pp. 314-319.

KAUFMANN, R.K., S. DEES, P. KARADELOGLOU, and M. SANCHEZ (2004). "Does OPEC Matter? An Econometric Analysis of Oil Prices", The Energy Journal 25 (4), pp. 67-90.

KOLLIAS, C., C. KYRTSOU, and S. PAPADAMOU (2013). "The Effects of Terrorism and War on the Oil Price-Stock Index Relationship”, Energy Economics 40 (6), pp. 743-752.

LIN, S.X. and M. TAMVAKIS (2010). "OPEC Announcements and Their Effects on Crude Oil Prices", The Energy Journal 38 (2), pp. 1010-1016.

LODERER, C. (1985). “A Test of OPEC Cartel Hypothesis: 1974-1983”, Journal of Finance 40 (3), 991-1006. 
LOPEZ, E. and E. MUÑOZ (2012). "Oil Price: Geopolitical Tensions and Production Events", [bodytext in Spanish; appendix in English] Working Paper 680, Central Bank of Chile.

MACAVOY, P.W. (1982). Crude Oil Prices: As Determined by OPEC and Market Fundamentals, Harper \& Row, Balinger, Cambridge, UK.

MAGHYEREH, A.I., B. AWARTANI, and E. BOURI (2016). "The Directional Volatility Connectedness between Crude Oil and Equity Markets: New Evidence from Implied Volatility Indexes", Energy Economics 57, pp. 78-93.

MALIK, F. and S. HAMMOUDEH (2007). "Shock and Volatility Transmission in the Oil, US and Gulf Equity Markets", International Review of Economics and Finance 16 (3), pp. 357-368.

MEDEL, C.A. (2015). "Fuelling Future Prices: Oil Price and Global Inflation", Nottingham Economic Review 16 (September), pp. 22-25.

MEDEL, C.A. (2016). "Un Análisis de la Capacidad Predictiva del Precio del Cobre sobre la Inflación Global", Economía Chilena 19 (2), pp. 128-153.

MENSI, W., S. HAMMOUDEH, and S.-M. Yoon (2014). "How Do OPEC News and Structural Breaks Impact Returns and Volatility in Crude Oil Markets? Further Evidence from a Long Memory Process", Energy Economics 42, pp. 343-354.

MORAN, T. (1982). "Modeling OPEC Behaviour: Economic and Political Alternatives", in G.M. Griffin and D.J. Teece (Eds.), OPEC Behaviour and World Oil Prices, Allen \& Unwin, London, UK.

NEELY, C.J. and D.E. RAPACH (2011). "International Comovements in Inflation Rates and Country Characteristics", Journal of International Money and Finance 30 (7), pp. 1471-1490.

NEWEY, W.K. and K.D. WEST (1987). "A Simple, Positive Semi-definite, Heteroskedasticity and Autocorrelation Consistent Covariance Matrix", Econometrica 55 (3), pp. 703-708.

ORGANISATION OF THE PETROLEUM EXPORTING COUNTRIES (2012). “OPEC Statute”, retrieved on 27 November, 2019.

PATTERSON, K. (2000). An Introduction to Applied Econometrics. A Time Series Approach, Macmillan Press, UK.

PINDYCK, R.S. (1978). "Gains to Producers from the Cartelisation of Exhaustible Resources", Review of Economics Statistics 60 (2), pp. 238-251.

POLLET, J.M. (2005). "Predicting Asset Returns with Expected Oil Price Changes", available at Social Science Research Network.

SAIZ, A. and U. SIMONSOHN (2013). "Proxying for Unobservable Variables with Internet Documentfrequency", Journal of the European Economic Association 11 (1), pp. 137-165.

SALANT, S.W. (1976). "Exhaustible Resources and Industrial Structure: A Nash-Cournot Approach to the World Oil Market”, Journal of Political Economy 84 (5), pp. 1079-1093.

SCHMIDBAUER, H. and A. RÖSCH (2012). "OPEC News and Announcements: Effects on Oil Price Expectation and Volatility", Energy Economics 34, pp. 1656-1663.

SCOTTI, C. (2016). "Surprise and Uncertainty Indexes: Real-time Aggregation of Real-activity Macrosurprises", Journal of Monetary Economics 82, pp. 1-19.

SMITH, J. (2005). "Inscrutable OPEC? Behavior Test of the Cartel Hypothesis", The Energy Journal 26 (1), pp. 51-82.

TAYLOR, J. and P.V. van Doren (2005). "The Case Against the Strategic Petroleum Reserve", Cato Institute: Policy Analysis 555, pp. 1-21.

TEECE, D. (1982). "OPEC Behaviour: An Alternative View”, in G.M. Griffin and D.J. Teece (Eds.), OPEC Behaviour and World Oil Prices, Allen \& Unwin, London, UK.

TUKEY, J. (1958). "Bias and Confidence in Not Quite Large Samples", Annals of Mathematical Statistics 29 (2), pp. 614.

WIRL, F. and A. KUJUNDZIC (2004). "The Impact of OPEC Conference Outcomes on World Oil Prices", The Energy Journal 25 (1), pp. 45-61.

WHITE, H. (1980). "A Heteroskedasticity-Consistent Covariance Matrix Estimator and a Direct Test for Heteroskedasticity”, Econometrica 48 (4), pp. 817-838. 


\section{APPENDIX A:}

\section{GT\&N VARIABLE DESCRIPTION}

In this appendix, we provide extended descriptions of the 10 dummy variables used in the construction of the $G T \& N$ variable. A time series plot of the 10 variables is presented in Figure A1.

1. United Nations Oil for Food Program (1995-2003) [+]. Programme developed by the United Nations established in 1995 as a response to Iraqi citizen's claims affected by economic sanctions imposed in the aftermath of Gulf War of 1991. The programme allows Iraq to sell petroleum in world markets in exchange for food, medicines, and other humanitarian help, aiming to bind Iraqi military capacity. The programme finishes in 2003. The events referred to this programme are United Nations' resolutions on Iraqi global oil market quotas, similar to the impact of new discoveries.

2. United States relations with Libya and Iran (1996-2004) [-]. Events considered in this category are related to the sanctions imposed on Iran and Libya promulgated in 1996. This act imposes economic sanctions on entrepreneurial-kind relations with Iran and Libya. The programme is a response to the nuclear agenda and support provided by Iran to certain terrorist associations (Hezbolla, Hammas, and Jihad). On 19 December, 2003, Libya announced its intention to leave the nuclear programme as well as the development of massive destruction weapons and the beginning of a new era of cooperation with the United States.

3. Iraq War and post-war period (2003-2011) [-]. News related to the United States' invasion to Iraq in March 2003, and Saddam Hussein's capture in December 2003. It also includes events related to the installation of the provisional government in Iraq and reestablishment of Iraq's international affairs.

4. Iran post Iraq War (start in 2005) [-]. Accounts for events related to justified hearsays of the re-establishment of a nuclear programme during the administration of president Mahmoud Ahmadinejad starting in August 2005.

5. Terrorist attacks [-]. Constitutes events referred to terrorist attacks to productive installations in the Middle East, or terrorist targets. 9/11 attacks are included within this category.

6. Lebanon War (2006) [-]. Also referred as Israel-Hezbolla War o July War, is a 34-day-long conflict occurred in Lebanon spanning from 12 July to 14 August, 
2006, after a ceasefire, statement of the United Nations. The conflict had a de facto end on 8 September, 2006 when Israel unblocked maritime restrictions over Lebanon.

7. Arab Spring (2011) [-]. Constitute waves of anti-government demonstrations and strikes in Arab countries starting on 18 December, 2010 in Tunisia. Governments of Tunisia, Egypt, Libya, and Yemen were overthrown. Civilian demonstrations took place in Bahrain and Syria; massive movement strikes in Algeria, Iraq, Jordan, Kuwait, Morocco, and Oman; minor events were noticed also in Lebanon, Mauritania, Saudi Arabia, Sudan, and Western Sahara.

8. Use of the United States Strategic Petroleum Reserve [+]. The Strategic Petroleum Reserve (SPR) is the world's greatest for-emergency reserve of oil, whose capacity achieves more than 700 million of barrels. This variable accounts for the United States announcements on sales with stabilisation purposes or domestic emergencies. An in-depth and up-to-date analysis of the use of the SPR can be found in Demirer and Kutan (2010).

9. New announcements on discoveries, and site exploration [+]. News related to oilfield discoveries, explorations, drills, and strategic alliances between firms in order to exploit Middle East oilfields.

10. Purely OPEC announcements [+/-]. Announcements on OPEC's quotas reassignment or major maintenance works. This variable by itself constitutes the $G T \& N-O$ measure. In contrast, the sum of the previous nine make up $G T \& N-N O$. 
FIGURE A1

$G T \& N$ VARIABLE COMPOSITION: ALL EVENTS $(*)$

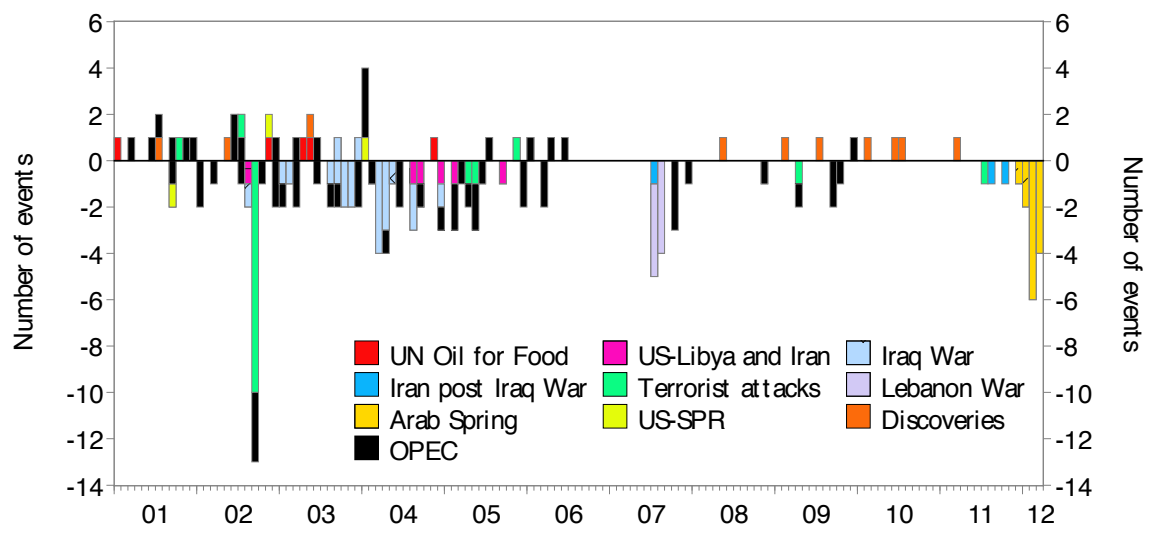

(*) Sample: 2001.1-2012.3. Source: Authors' calculations using data from López and Muñoz (2012). 


\section{APPENDIX B:}

\section{ROBUSTNESS RESULTS USING THE JACKKNIFE ESTIMATOR}

Baseline results of Tables 3-5 suggest that all considered geopolitical tensions and news do affect the oil price, its forecasts and the dispersion around those forecasts. Moreover, non-OPEC news and tensions also cause the current oil prices as well as forecasts and its dispersion in immediate time. Finally, OPEC news and tensions are caused by oil prices and exhibit a feedback relationship with oil price forecasts' dispersion. This relegates OPEC as a source of information for oil price expectations formation and are ultimately a wider range of geopolitical tensions and news affecting actual oil price.

In this appendix, we perform the same analysis making use of the jackknife coefficients' standard deviation instead of the Newey-West estimator. The results using the $G T \& N$ variable are reported in Table B1. The first panel indicates that the fifth lag of geopolitical tensions and news cause the oil price, supported by the rejection of serial correlation hypothesis (baseline results are significant from the third lag onwards). Similar to the baseline results, H1 Inverse indicates that the relationship is unidirectional from $G T \& N$ to the oil price. The second panel shows that geopolitical tensions and news cause oil price forecasts from the fifth lag to sixth, and there is not a feedback relationship between variables. The results are supported by non-autocorrelated residuals and are qualitatively similar to baseline results. In the same line, the third panel also reveals a feedback relationship between $G T \& N$ and oil price forecasts' dispersion, meaning that tensions and news affect current oil prices and, at the same time, the dispersion triggers news and tensions on oil supplier countries.

The results using purely OPEC news are presented in Table B2. The first panel provides similar results to baseline estimations, rejecting the causality of OPEC's geopolitical tensions and news to oil prices, but supporting the causality the other way around-from actual oil price to OPEC tensions and news. A small twist compared to baseline results is found in the second panel in which, besides OPEC causality of oil price forecasts, the latter cause the former with the first lag, transforming the link between both variables into a feedback relationship. Notice that the first lag of the forecast series causing OPEC tensions and news is not necessarily invalidating when considering that the current price actually causes OPEC news and tensions. It is likely that, in a persistent series such as oil price, lags of actual variable determine its one-step-ahead forecast. Interestingly, the third panel suggests that OPEC tensions and news cause forecast dispersion with the third lag, and also the causality goes in the opposite direction. This result supports the core claim of this article, giving a secondary role to OPEC as price setter, but still being relevant for forecasters and expectations formation. 


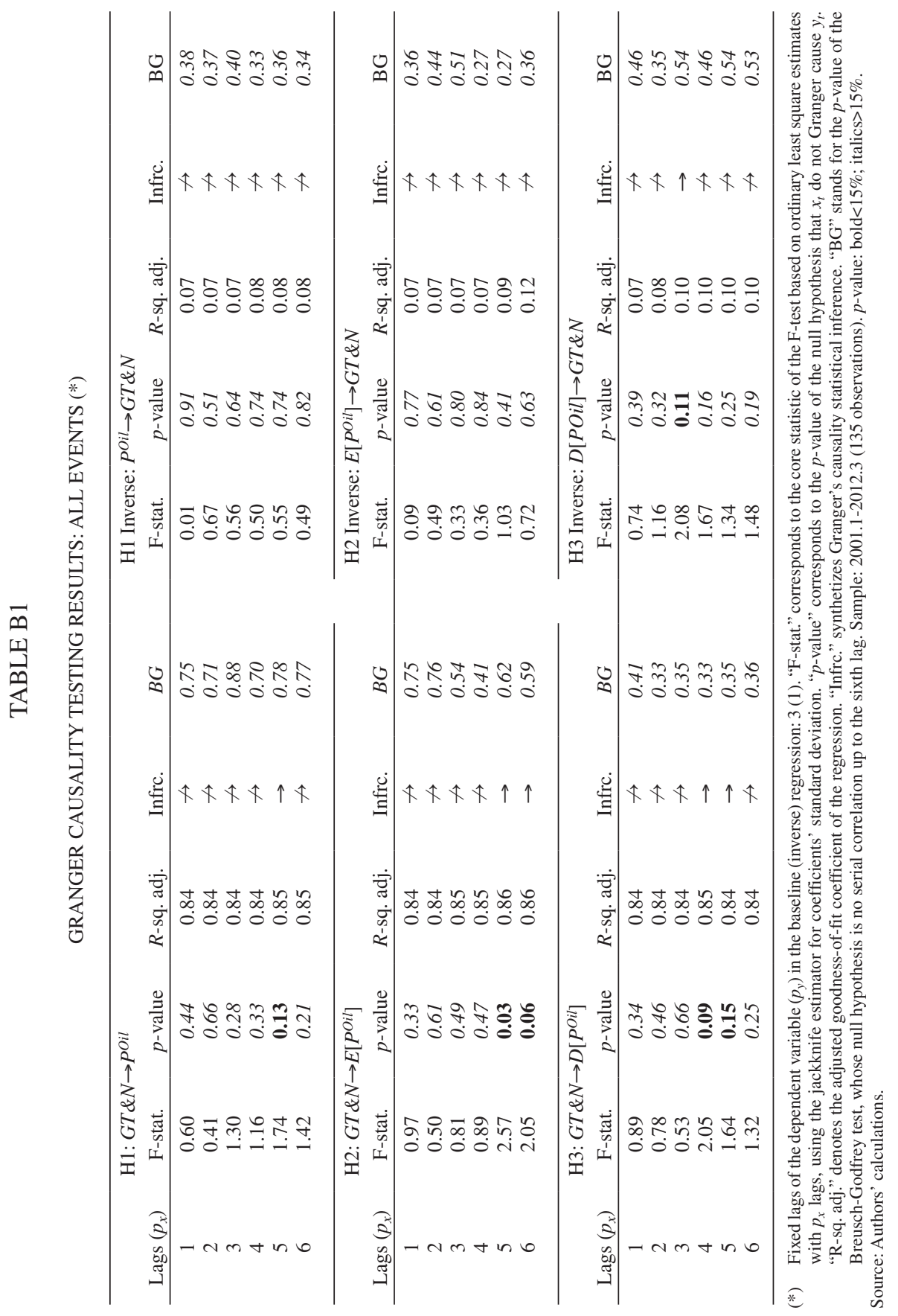




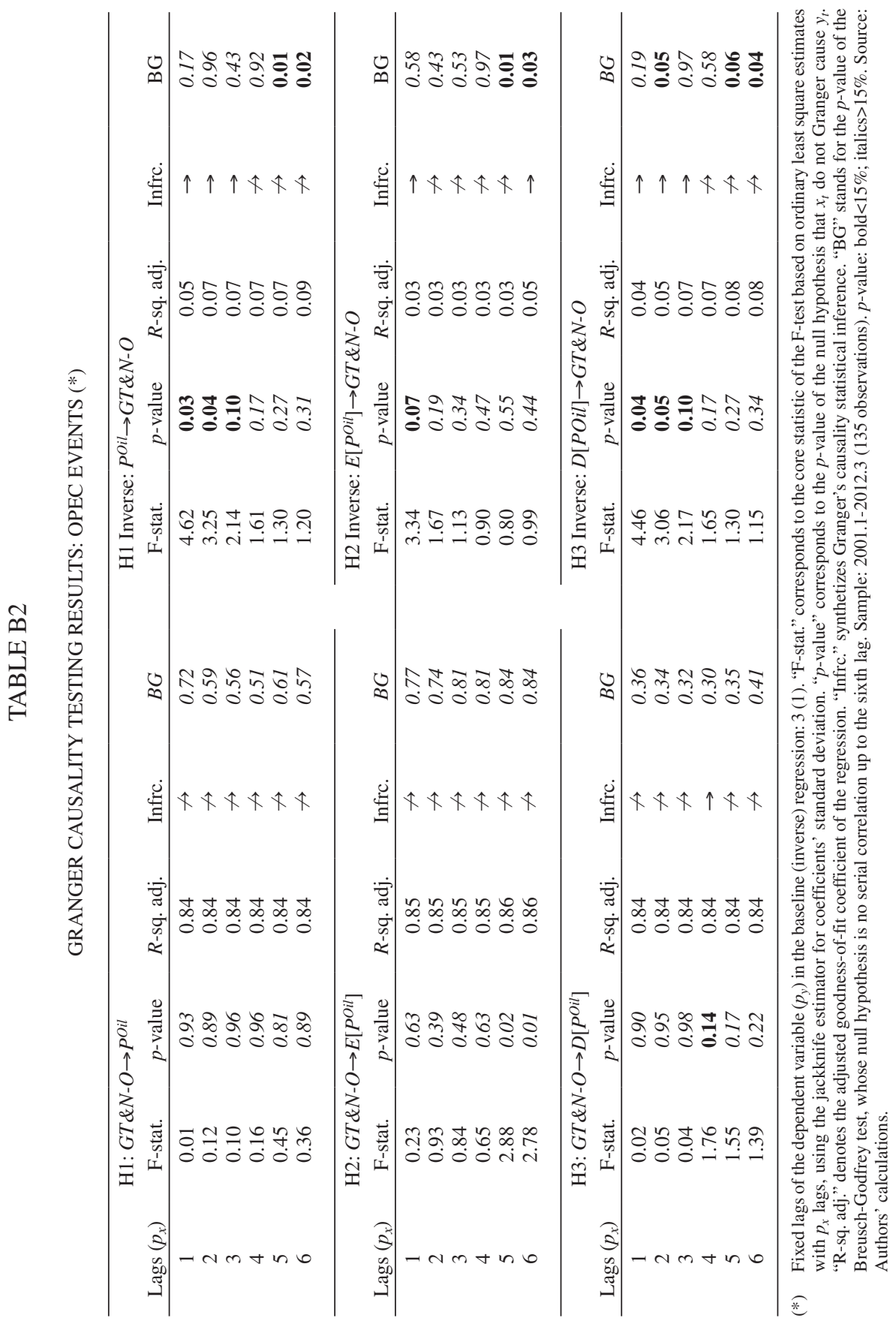




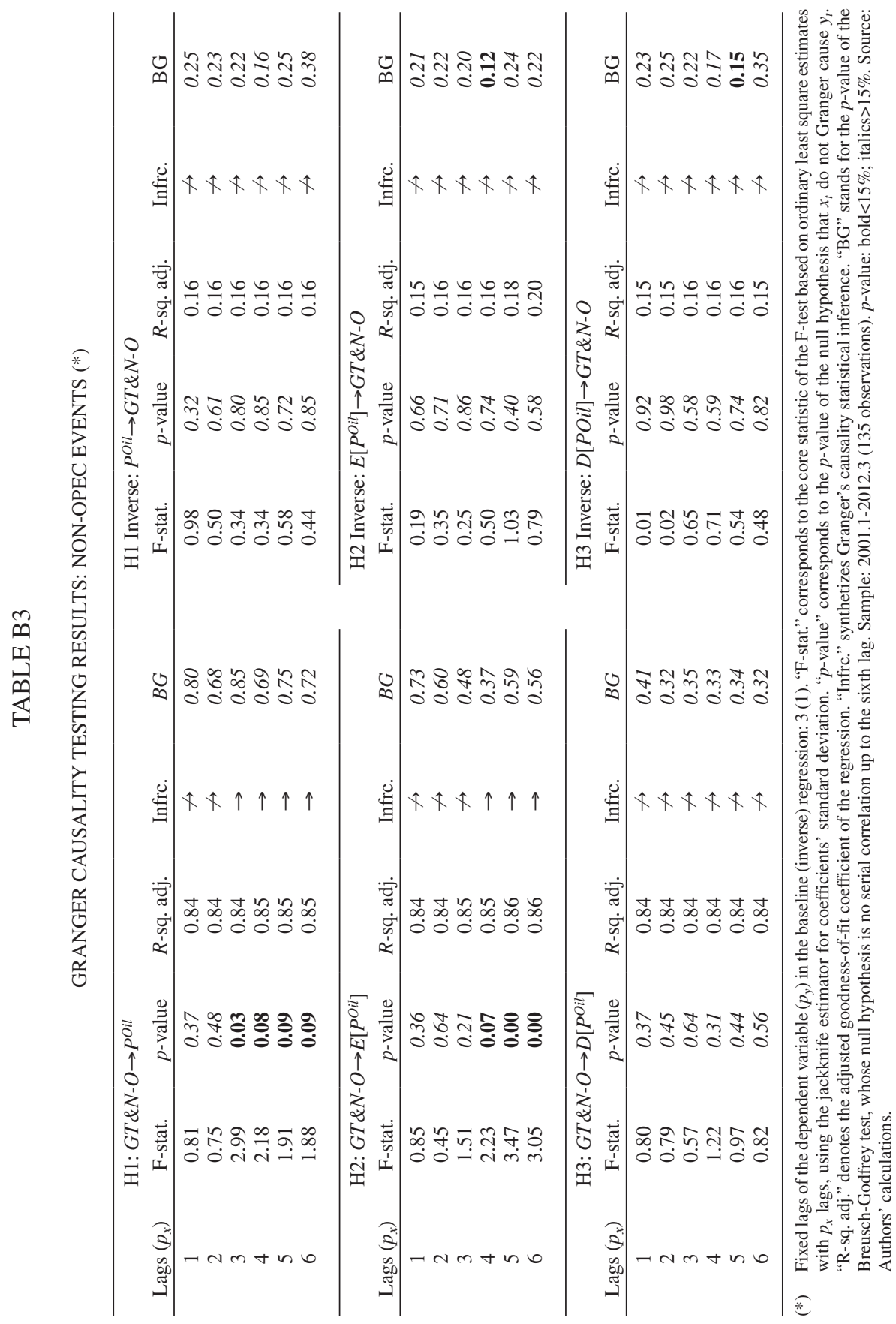


Finally, the results using non-OPEC geopolitical tensions and news are presented in Table B3. First and second panels are virtually the same to those of Table 5, with $G T \& N-N O$ causing both the oil price and its forecasts. Both relationships are unidirectional and supported by residuals' non-autocorrelation, confirming that there are a broad range of events that affect oil prices, and not necessarily those OPEC-based only. The third panel establishes an independent, no-relationship between non-OPEC geopolitical tensions and news and oil price forecasts' dispersion. The baseline results find that the first lag of $G T \& N-N O$ causes forecasts' dispersion, which is now eroded, and the $G T \& N-N O$ role is relegated to affect level forecasts only. This discrepancy reflects the methodological difference between the estimators; thus, suggesting that a few observations (likely coinciding with those with more intensity) command the causality of $G T \& N-N O$ over the forecasts' dispersion.

In sum, qualitative robustness results remain, but in some cases, the statistical inference comes out "weaker" than the baseline estimations. By "weaker" we mean finding fewer statistically significant cases when testing any proposed hypothesis, but still supporting the baseline conclusions. 